\title{
EFFECT OF SPINNING PARAMETERS ON PLA/PPC/CURCUMIN MICROFIBER DIAMETER: AN INVESTIGATION VIA RESPONSE SURFACE METHODOLOGY
}

\author{
SHARIFAH IMIHEZRI SYEd SHAHARUdDIN ${ }^{1 *}$, AMIRUL AKMAl FAUZAN ${ }^{1}$, \\ MOHAMAD FARIS IZZUdIN MOHAMAD JAZI ${ }^{1}$, NUR ATIQAH MOHD. AKHIR ${ }^{1}$, \\ Maizatulnisa Othman ${ }^{1}$, NOR Khairushima MUhamad Khairussaleh ${ }^{1}$, \\ NORHASHIMAH SHAFFIAR ${ }^{1}$ AND ZAIMAH HASAN ${ }^{2}$ \\ ${ }^{1}$ Department of Manufacturing and Materials Engineering,
} Kulliyyah of Engineering International Islamic University Malaysia, Gombak, Malaysia ${ }^{2}$ Mechanical Engineering Department, College of Engineering, Universiti Tenaga Nasional, Kajang, Malaysia

*Corresponding author: shaimihezri@iium.edu.my

(Received: $16^{\text {th }}$ January 2020; Accepted: $4^{\text {th }}$ March 2020; Published on-line: $4^{\text {th }}$ July 2020)

\begin{abstract}
The initial phase of this study was to investigate the effect of polypropylene carbonate (PPC) additions in polylactic acid (PLA)/curcumin (Cur) blends. It was observed that the presence of curcumin particulates behaved as a reinforcement filler for PPC additions up to $30 \mathrm{wt} \%$. A specific composition was then invested to find the correlation between the fiber diameter and melt-spinning process parameters using central composite design (CCD), a subset of response surface methodology (RSM). Results showed that the spinning temperature had a greater effect than the spinning speed on the diameter of PLA/PPC/curcumin fiber. The response model indicated a good correlation between experimental and predicted values since the ANOVA analysis demonstrated high $F$ value of model adequacy at 10.34, non-significant lack of fit, precision adequacy of 9.94 and $\mathrm{R}^{2}$ value of 0.80 . Therefore, this model can be used in a future study to establish the processing parameters for controlled fiber production.
\end{abstract}

ABSTRAK: Fasa awal kajian ini adalah bagi mengkaji kesan penambahan karbonat polipropilin ke dalam campuran asid prolaktik (PLA)/kurkumin (Cur). Didapati kehadiran zarah-zarah kurkumin bertindak sebagai pengisi bantuan pada penambahan PPC sehingga $30 \mathrm{wt} \%$. Komposisi tertentu kemudian dikaji bagi mencari kaitan diameter fiber dan parameter proses putaran-cair menggunakan rekaan komposit utama (CCD), dan subset metodologi gerak-balas permukaan (RSM). Keputusan menunjukkan suhu putaran berpengaruh besar berbanding kelajuan putaran pada diameter fiber PLA/PPC/kurkumin. Model yang bertindak balas ini menunjukkan kaitan yang baik antara eksperimen dan nilai yang dijangka kerana analisis ANOVA menunjukkan nilai- $F$ yang tinggi pada 10.34 kecukupan model, tidak-ketara kurang padanan, kecukupan ketepatan pada 9.94 dan nilai $\mathrm{R}^{2}$ sebanyak 0.80 . Oleh itu, model ini boleh digunakan pada kajian akan datang bagi menghasilkan parameter proses pengeluaran fiber kawalan.

KEYWORDS: poly(lactic acid); curcumin; poly(propylene carbonate); fiber; RSM 


\section{INTRODUCTION}

Poly(lactic acid) (PLA) biopolymer has been extensively studied for biomedical applications due to its high mechanical strength and modulus [1]. PLA can be used with non-toxic and non-carcinogenic effects in the human body [2,3] since its by-products such as lactic acid and its short oligomers, $\mathrm{H}_{2} \mathrm{O}$ and $\mathrm{CO}_{2}$, are internally metabolized. However, brittleness has been one of its main drawbacks since it limits the flexibility of the polymer [4]. The physical properties of PLA can be attuned for specific applications by blending (solvent or melt blending techniques) [5] with biodegradable polymers such as polypropylene carbonate (PPC) [6]. PPC is produced through a copolymerization process of $\mathrm{CO}_{2}$ /propylene oxide (PO) [7]. The resulting copolymer chains are comprised of homopolymer propylene oxide and alternating carbon dioxide and propylene segments [8]. Despite the similar chemical structure between PLA and PPC [9]., Ning et al. [10] and Ma et al. [11] studies on PLA/PPC blends suggested that the two polymers are partially miscible when mixed.

Curcumin, a naturally active compound derived from turmeric (Curcuma longa), is well known for its antibacterial, antitumor, and antioxidant properties [12-14]. Antimicrobial agent derived from natural sources does not display typical side effects as observed for synthetically produced chemicals [15]. In-vivo and in-vitro studies revealed that curcumin promotes bioactivities by inducing cell apoptosis, inhibiting cell proliferation, anti-cell adhesion and motility, and imparting anti-microbe properties [16]. PLA membranes loaded with curcumin (1-5 wt \%) have been previously reported [17.18]. The incorporation of bioactive particulates into polymer fiber, however, affects the strength of the fiber with increasing particulate content [19]. Thus, one of the greatest challenges in manufacturing these novel therapeutic-eluting fibers lies in attaining considerable drug amounts and therapeutic properties without compensating the suture's mechanical and release kinetic properties.

Response surface methodology is prevalently used to develop a mathematical loworder polynomial expression by approximating physical experimental data [20]. One of the main advantages of RSM is the ability to establish a true relationship between the dependent variable or response $(Y)$ and a range of independent variables $(X)$. RSM also gives a low standard of error and thus has been considered as a reliable optimization tool [21]. Previously, RSM has been employed in an abundant number of works to study the correlation between process/materials and fiber properties that were produced via the melt spinning process $[22,23]$ as well as the electrospinning process $[20,24,25]$.

This study was spurred by our previous success in the melt-spinning of PLA/curcumin microfiber [26]. However, the addition of curcumin filler into PLA resulted in a more viscous blend and the resultant melt-spun fibers were also found to be brittle and lack the desired flexibility. Thus, this study aims to address the brittle issue of PLA/curcumin by adding plasticizer such as PPC. The resultant polymer blends were characterized via tensile test. A specific composition with reasonable strength and modulus was then selected to investigate the interactive effects of the melt spinning process parameters (spinning speed and spinning temperature) on the fiber diameter using RSM. This work provides a processing route for mass production of biodegradable fibers containing therapeutic agents that can potentially be used for suture, ligament reconstruction, and in self-reinforced composite $[27,28]$. 


\section{METHODOLOGY}

\subsection{Materials Preparation}

PLA (IngeoTM Biopolymer 3052D) from Natureworks (USA), PPC (QPAC 40) from Empower Materials (Malaysia) and curcumin (Pahang Pharmacy Sdn. Bhd., Malaysia) were dissolved in chloroform (R\&M Chemicals, United Kingdom). Before the solvent blending process, both PLA and PPC pellets were dried at $70^{\circ} \mathrm{C}$ and $40^{\circ} \mathrm{C}$ respectively for 2 hours in an oven. The PLA/curcumin/PPC blends at different weight \% ratios as shown in Table 1 were dissolved in chloroform at a ratio of 1:10 and stirred for 1 hour at room temperature. The completely dissolved mixture was then poured into a tray. The polymer blend solutions were reduced into thin films once the chloroform has fully evaporated.

Table 1: Composition of PLA/curcumin/PPC used in this study.

\begin{tabular}{cccc}
\hline \multirow{2}{*}{ Code } & \multicolumn{3}{c}{ Ratio (wt.\%) } \\
\cline { 2 - 4 } & PLA & Curcumin & PPC \\
\hline PLA_Cur_PPC 10 & 89 & 1 & 10 \\
PLA_Cur_PPC 20 & 79 & 1 & 20 \\
PLA_Cur_PPC 30 & 69 & 1 & 30 \\
PLA_Cur_PPC 40 & 59 & 1 & 40 \\
PLA_Cur_PPC 50 & 49 & 1 & 50 \\
\hline
\end{tabular}

\subsection{Tensile Test}

Thin films were cut according to the ASTM D882 dimension of $50 \mathrm{~mm} \times 10 \mathrm{~mm} \times 0.80$ $\mathrm{mm}$ with an extra $10 \mathrm{~mm}$ at both ends for clamping purposes. The tests were performed using a Shimadzu Universal Tensile Machine (AGS-10K NXD) at a crosshead speed of 20 $\mathrm{min} / \mathrm{mm}$ and a load cell of $5 \mathrm{kN}$. The average and standard deviation of tensile strength, modulus and percent elongation were calculated from the load-elongation curve based on 5 samples.

\subsection{Mutivariate Design of Experiment}

Before determining the design space, the range of available spinning speed as well as the temperature range for continuous fiber spinning was determined. The in-house built mini fiber drawing tower has the capacity to spin fiber from 250 to $390 \mathrm{rpm}$. Preliminary experimental works showed that the intended composition can be successfully drawn/spun within a melt viscosity region corresponding to $160{ }^{\circ} \mathrm{C}-173^{\circ} \mathrm{C}$.

In this study, central composite design (CCD) which is a subset of RSM was used to develop the regression model. The model represents the response of fiber diameter $(Y)$ for two design factors or independent variables represented by $X_{1}$, spinning temperature and $X_{2}$, spinning speed. The total number of runs suggested by CCD was based upon the following equation:

$$
\mathrm{N}=2^{\mathrm{k}}+2 \mathrm{k}+\mathrm{n}_{0}
$$

where $2^{\mathrm{k}}=$ represents the two-level factorial points,

$\mathrm{k}=$ axial points located at “ $\pm \sqrt{ } \mathrm{k}$ ” from the centre points of experimental domain

$\mathrm{n}_{0}=$ central point replicates.

The $2 \mathrm{k}$ (axial points) is used during screening and readability for variance of model prediction and the $\mathrm{n}_{0}$ (central points) is very crucial to obtain an independent estimate of the 
design experimental error [29]. The design factors or independent variables (in this study, $\mathrm{k}=2$ for spinning temperature and spinning speed) were considered at two levels; low (-) and high $(+)$ as shown in Table 2. Therefore, the total number of proposed experiments is 13 based on: $2^{\mathrm{k}}\left(2^{2}=4\right.$ : factorial points $)+2 \mathrm{k}(2 \times 2=4$ axial points $)+5\left(\mathrm{n}_{0}=5\right.$ replications $)$. Fig. 1 shows the schematic of the experimental design. The CCD design matrices in coded/uncoded values for the design of experiment are listed in Table 3. The ANOVA analysis and statistical values were determined using Design Expert software (version $6.0 .8)$.

Table 2: CCD coded and uncoded values of the input variables for the experimental design

\begin{tabular}{cccccc}
\hline Codes levels & Lowest & Low & Center & High & Highest \\
Variables & $-\sqrt{ } 2$ & -1 & 0 & 1 & $\sqrt{2}$ \\
\hline$\left(X_{I}\right)$ Spinning temperature $\left({ }^{\circ} \mathrm{C}\right)$ & 157 & 160 & 166.5 & 173 & 176 \\
$\left(X_{2}\right)$ Spinning speed $(\mathrm{rpm})$ & 221 & 250 & 320 & 390 & 419 \\
\hline
\end{tabular}

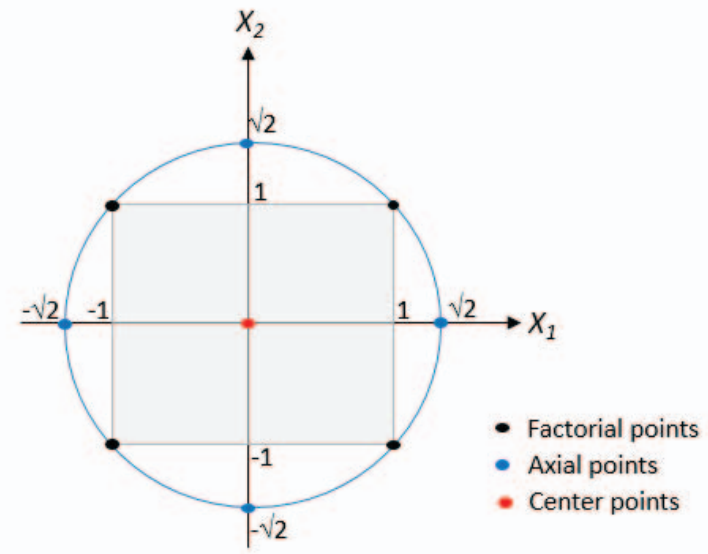

Fig. 1: Schematic diagram of central composite design (CCD) with $2^{2}$ factorial design based on $X_{l}$ (spinning temperature) and $X_{2}$ (spinning speed) variables.

Table 3: CCD design matrices in coded and uncoded values for the design of experiment of melt spinning process.

\begin{tabular}{ccccc}
\hline \multirow{2}{*}{ Run No. } & \multicolumn{2}{c}{$\begin{array}{c}\text { Design factor } \\
\text { in coded value }\end{array}$} & \multicolumn{2}{c}{$\begin{array}{c}\text { Design factor } \\
\text { in uncoded value }\end{array}$} \\
\cline { 2 - 5 } & $\boldsymbol{X}_{\boldsymbol{I}}$ & $\boldsymbol{X}_{\boldsymbol{2}}$ & $\begin{array}{c}\text { Spinning } \\
\text { temperature }\left({ }^{\circ} \mathbf{C}\right)\end{array}$ & $\begin{array}{c}\text { Spinning speed } \\
(\mathbf{r p m})\end{array}$ \\
\hline 1 & 0 & $-\sqrt{2}$ & 166.5 & 221 \\
2 & 1 & 1 & 173 & 390 \\
3 & -1 & 1 & 160 & 390 \\
4 & -1 & -1 & 160 & 250 \\
5 & $\sqrt{ } 2$ & 0 & 176 & 320 \\
6 & $-\sqrt{2}$ & 0 & 157 & 320 \\
7 & 0 & 0 & 166.5 & 320 \\
8 & 0 & $\sqrt{2}$ & 166.5 & 419 \\
9 & 0 & 0 & 166.5 & 320 \\
10 & 0 & 0 & 166.5 & 320 \\
11 & 0 & 0 & 166.5 & 320 \\
12 & 0 & 0 & 166.5 & 320 \\
13 & 1 & -1 & 173 & 250 \\
\hline
\end{tabular}




\subsection{Melt-drawn Spinning Setup}

The fibers from PLA_Cur_PPC 30 were spun via an in-house built melt spinning process as shown in the schematic representation in Fig. 2. In this process, the crushed thin film was melted above the melting temperature for extrusion through a circular shaped orifice at the nozzle and then stretched into monofilament fiber by the speed of the take-up rotating wheel. The fibers were rapidly cooled by the ambient air as they emerged from the nozzle. The melt spinning process used is also known as vertical spinning since no mechanical means such as extruder is used to force the flow through the nozzle. Instead, the polymer moves simply by the force of gravity.

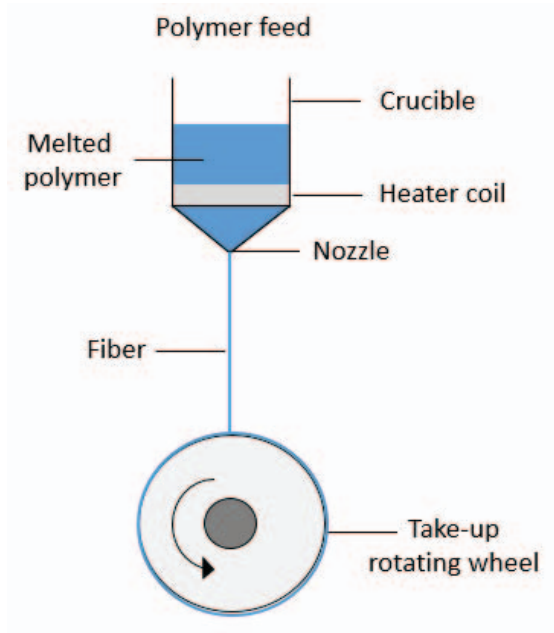

Fig. 2: Schematic representing the melt spinning experimental setup.

\subsection{Fiber Morphology}

The diameter of PLA_Cur_PPC 30 fibers was measured via optical microscope (BX41M) (Olympus Microscopes, UK). The diameter was taken as an average of 20 different fibers for each composition. The resulting fiber physical structure was then observed via scanning electron microscope (SEM) (JEOL, JSM-IT 100; Japan) with 200x magnifications at $10 \mathrm{kV}$. All fibers were prepared by sputter coating with palladium using Polaron SC7620.

\section{RESULTS AND DISCUSSION}

\subsection{Tensile Test}

The amount of filler particulates significantly affects the ease of processing and quality of the fibers obtained [26]. In this study, the amount of curcumin was limited to only $1 \mathrm{wt} \%$ since previous studies $[26,30]$ had shown that increasing the curcumin content corresponds with a further decrease in strength. The tensile test was performed to determine the effect of PPC on PLA/curcumin blend.

In this study, it can be seen from Fig. 3 that the strength was maintained as PPC was incorporated up to $30 \mathrm{wt} \%$. However, previous studies have shown that there was an immediate decrease in strength and modulus when PPC was incrementally added into neat PLA [9,31,32]. Thus, it is postulated that the observed strength retention was attributed to the presence of curcumin particulate that had behaved as a reinforcing filler $[33,34]$. PPC also has an inherently lower tensile strength in comparison to PLA [35]. Thus, further 
additions of PPC (>30 wt $\%)$ are believed to have weakened the intermolecular strength of the polymer blend which subsequently cancelled the curcumin reinforcement effect $[11,31]$.

A comparison between Fig. 4 and Fig. 5 revealed that the elongation \% trend is inversely proportional to Young's modulus trend. It is also observed that at $30 \mathrm{wt} \% \mathrm{PPC}$, reversal trend occurred for both modulus and elongation. Other than the contribution of Young's modulus of each constitutive polymer in the blend, other factors may have contributed to the observed modulus and elongation trend such as phase morphology and selective localisation [11]. In most cases, the major constituent in the polymer blend will form the continuous phase whilst the minor constituent will form as scattered spherical droplets [36]. SEM studies on binary PLA/PPC system [37,38] revealed that at $30 \mathrm{wt} \%$ PPC addition, the blend resembles typical sea-island morphology in which the PLA phases coalesce together and surround the PPC droplets. At $50 \mathrm{wt} \%$ PPC, the existing sea-island morphology is transformed into co-continuous morphology. Consequently, the PPC phase progressed from droplets into elongated and interconnected structures. Particulates or fillers added into the polymeric blend may be dispersed at the phase interphase or in either phase of the multi-component blend. Studies have shown that during mixing, particulates behave in a manner of selective localization whereby the particulates prefer to move and reside in the polymer phase that has sufficiently low viscosity $[39,40]$. Such selective localization tendency induces better particulate dispersion and has been observed in various systems of filler/matrix composites [42,42].

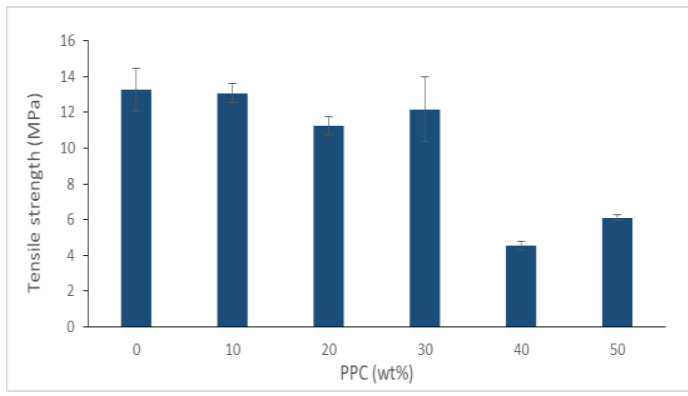

Fig. 3: Tensile strength properties of PLA/curcumin/PPC blends.

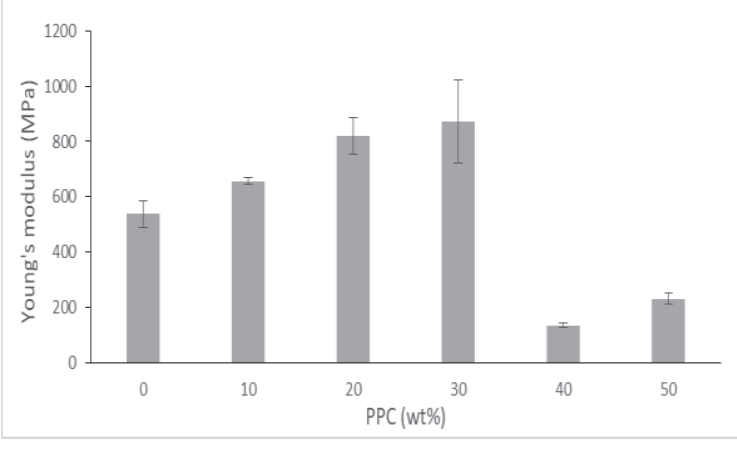

Fig. 4: Young's modulus properties of PLA/curcumin/PPC blends.

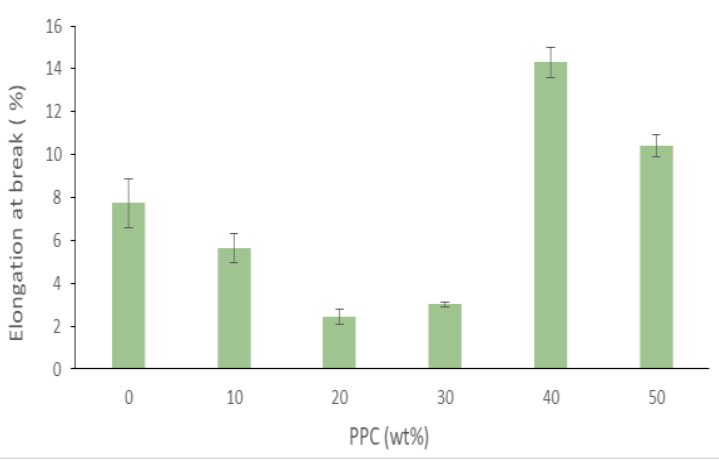

Fig. 5: Elongation at break properties of PLA/curcumin/PPC blends.

Thus, it is proposed that the parallel increase of Young's modulus with the increasing amount of PPC (inversely proportional effect on elongation \%) up to $30 \mathrm{wt} \% \mathrm{PPC}$, encourages better curcumin dispersion in the PPC phase since it is less viscous than PLA. The presence of these particulates impedes the slippage movement of PPC molecular chains. A study by Ning et al. [10] on PLA/PPC/carbon black (CB) particulate blend also revealed 
that greater particle dispersion was achieved in the PPC phase. At $40 \mathrm{wt} \% \mathrm{PPC}$, the size of the PPC droplets further increases [38] and the modulus drops drastically by $85 \%$ whilst the elongation \% increased tremendously by $400 \%$. Further additions of PPC at $50 \mathrm{wt} \%$ decrease the elongation \% of the blend. A similar drop in elongation \% was also observed by Gao et al. [37]. Hence, it is proposed that the localization of curcumin particles in the cocontinuous phase has contributed to the decrease in elongation \%. In this work, PLA_Cur_PPC 30 was selected as a case study for RSM due to its reasonably high strength and modulus properties.

\subsection{ANOVA Analysis and Response Model}

Fabrication of biopolymer fiber via the melt spinning process offers a simple, efficient and economical approach since solvent-free monofilament fiber can be manufactured at a fairly high rate $[43,44]$. Theoretically, the region of melt viscosity suitable for most polymer processing such as extrusion and melt spinning varies from $10^{2} \mathrm{~Pa} \cdot \mathrm{s}$ to $10^{5} \mathrm{~Pa} \cdot \mathrm{s}$ [44]. The obtained responses (fiber diameter) for the CCD design matrices are tabulated in Table 4.

Table 4: Design factors in coded and uncoded values and their responses.

\begin{tabular}{|c|c|c|c|c|c|}
\hline \multirow{2}{*}{$\begin{array}{l}\text { Run } \\
\text { No. }\end{array}$} & \multicolumn{2}{|c|}{$\begin{array}{l}\text { Design factor } \\
\text { in coded value }\end{array}$} & \multicolumn{2}{|c|}{$\begin{array}{l}\text { Design factor } \\
\text { in uncoded value }\end{array}$} & \multirow{2}{*}{$\begin{array}{c}\text { Response } \\
\begin{array}{c}\text { Average fiber } \\
\text { diameter } \\
(\mu \mathrm{m})\end{array}\end{array}$} \\
\hline & $X_{1}$ & $X_{2}$ & $\begin{array}{c}\text { Spinning } \\
\text { temperature }\left({ }^{\circ} \mathrm{C}\right)\end{array}$ & $\begin{array}{l}\text { Spinning speed } \\
\text { (rpm) }\end{array}$ & \\
\hline 1 & 0 & $-\sqrt{2}$ & 166.5 & 221 & 26.2 \\
\hline 2 & 1 & 1 & 173 & 390 & 28.7 \\
\hline 3 & -1 & 1 & 160 & 390 & 14.7 \\
\hline 4 & -1 & -1 & 160 & 250 & 28.5 \\
\hline 5 & $\sqrt{ } 2$ & 0 & 176 & 320 & 36.7 \\
\hline 6 & $-\sqrt{2}$ & 0 & 157 & 320 & 30.4 \\
\hline 7 & 0 & 0 & 166.5 & 320 & 25.6 \\
\hline 8 & 0 & $\sqrt{2}$ & 166.5 & 419 & 21.1 \\
\hline 9 & 0 & 0 & 166.5 & 320 & 23.5 \\
\hline 10 & 0 & 0 & 166.5 & 320 & 26.3 \\
\hline 11 & 0 & 0 & 166.5 & 320 & 27.9 \\
\hline 12 & 0 & 0 & 166.5 & 320 & 28.4 \\
\hline 13 & 1 & -1 & 173 & 250 & 39.4 \\
\hline
\end{tabular}

The initial ANOVA analysis for the design factors for PLA_Cur_PPC 30 is shown in Table 5. The constructed response model was evaluated for its suitability to represent the experimental data based on the following criteria; model adequacy, lack-of-fit test, precision adequacy, and $\mathrm{R}^{2}$ value. The $p$-value statistically represents the significance measures of each design factor or parameter in explaining the variability for the response model. The parameter is considered to have an adequate or significant effect if its $p$-value is lower than 0.05 ( $\mathrm{p}<0.05$ degree of confidence limit).

The $F$-value for 'model adequacy' of 6.20 implies that the response model is significant and there is only a $1.65 \%$ chance that a "model $F$-value" this large could occur due to noise. The result also shows that the $F$-values for both terms (spinning temperature $X_{1}$ and spinning speed $X_{2}$ ) was significantly effective on the response trend with probability values of nearly $99 \%$. The quadratic terms $\left(X_{1}^{2}\right)$ were also significantly effective with a probability of more than $96 \%$. However, the quadratic term, $X_{2}^{2}$ and cross-product term $X_{1} X_{2}$ were greater than the significance level of $p=0.05$ and thus have no significant impact on 
the response trend. The $p$-value for the lack-of-fit test was not significant at $0.06(p>0.05)$, hence it was deduced that the model was able to satisfactorily fit the data. The signal-tonoise ratio or "adequacy precision" for the response model indicates an adequate signal at 9.032 since a value greater than 4 is highly desirable.

Table 5: Initial analysis of variance based on two design factors (spinning temperature, spinning speed) for the melt spinning process of PLA_Cur_PPC 30

\begin{tabular}{lcc}
\hline Source & F value & P value \\
\hline Temperature: $X_{1}$ & 11.66 & 0.0112 \\
Speed: $X_{2}$ & 10.25 & 0.0150 \\
$X_{1}^{2}$ & 6.60 & 0.0370 \\
$X_{2}^{2}$ & 1.34 & 0.2844 \\
$X_{1} X_{2}$ & 0.20 & 0.6713 \\
Model adequacy & 6.20 & 0.0165 \\
Lack of fit & 6.15 & 0.0559 \\
Adequate precision & & \\
(ratio $>4) \quad=9.032$ & & \\
$\mathrm{R}^{2} \quad=0.8157$ & & \\
\hline
\end{tabular}

The initial fitted second-order equation for the response and design factors is as follows:

$$
Y=26.34+4.23 X_{1}-3.96 X_{2}+3.41 X_{1}^{2}-1.54 X_{2}^{2}+0.78 X_{1} X_{2} \quad \text { (Eq. 2) }
$$

where $Y$ is the average fiber diameter, and $X_{1}$ and $X_{2}$ respectively represent the coded terms for spinning temperature and spinning speed. Both negative and positive signs respectively represent antagonistic effect and synergistic effect. The insignificant terms of $X_{2}^{2}$ and crossproduct term $X_{1} X_{2}$, were removed and ANOVA analysis was performed for the second time, yielding the results shown in Table 6 .

Table 6: Reduced analysis of variance based on two design factors (spinning temperature, spinning speed) for the melt spinning process of PLA_Cur_PPC 30.

\begin{tabular}{lcc}
\hline Source & F value & P value \\
\hline Temperature: $X_{1}$ & 12.28 & 0.0067 \\
Speed: $X_{2}$ & 10.81 & 0.0094 \\
$X_{1}^{2}$ & 7.94 & 0.0201 \\
Model adequacy & 10.34 & 0.0028 \\
Lack of fit & 4.68 & 0.0801 \\
Adequate precision & & \\
(ratio $>4) \quad=9.941$ & & \\
$\mathrm{R}^{2} \quad=0.7752$ & & \\
\hline
\end{tabular}

The reduced fitted second-order equation for the response and design factors is as follows:

$$
Y^{\prime}=25.27+4.23 X_{1}-3.96 X_{2}+3.61 X_{1}^{2}
$$

The $F$-value for 'model adequacy' in $\mathrm{Y}^{\prime}$ ' increases to 10.34 , with a $0.28 \%$ chance that the F-value obtained may occur due to noise. The "lack-of-fit" value was not significant at $0.08(p>0.05)$ and the adequacy precision is 9.941. The increase of $p$-values for the reduced model, $Y$ ' for 'lack-of-fit and the increase of adequate precision respectively means that the model is now better fitted and has a higher signal-to-noise ratio. The correlation coefficient, $\mathrm{R}^{2}$ is a criterion that is obtained from the fitted linear plot for a set of predicted values versus observed values and is used to evaluate the ability of the model to predict the result. The value of $\mathrm{R}^{2}$ for the final response model in this study statistically indicates that the model 
can explain reasonably well up to approximately $80 \%$ of the variation in the fiber diameter due to the two design factors.

The $F$-value associated with the $X_{1}$ term (spinning temperature) is higher than the $X_{2}$ term (spinning speed) and thus comparatively has a more significant effect on the response model (fiber diameter). Kong et al. [45] had also observed the pronounced effect of temperature on fiber diameter since it directly influences the physiochemical properties (melt viscosity, surface tension) of the polymer blend. On its own, PPC lacks the viscous flow necessary to produce continuous fiber due to its terminal chain of hydroxyl groups [46]. Thus, the addition of PPC is expected to lower the melt viscosity of the PLA/curcumin blend in this study [10]. Hypothetically, it was anticipated that the fabrication of nano-sized fibers of this composition may be slightly difficult since polymer melts are more viscous [45] in the order of one magnitude in comparison to the viscosity of polymer solutions [47]. Fig. 6 depicts an approximately linear probability plot and thus supports the condition that the error terms were distributed normally. The plot of predicted results against observed results is shown in Fig. 7. It can be seen from the graph that there is a satisfactory correlation between the diameter of the fiber with spinning temperature and spinning speed.

Fig. 8 visualizes the contoured plot of the predicted mean fiber diameter due to the effect of spinning temperature and spinning speed. The propitious condition for fiber fabrication via melt spinning process dictates that both the gravitational force and elongation force provided by the spinning speed must be able to overcome the combined forces exerted by viscosity and surface tension [48]. It can be seen that at any given spinning temperature, the fiber diameter decreases with increasing spinning speed due to the increasing elongation stress. It was also observed that at any constant spinning speed, the diameter of the fiber progressively increases with increasing temperature. In general, the increase in spinning temperature lowers the surface tension. As a result, the cohesive forces between the molecules to resist the increasingly fluidic polymer flow from the gravitational force and elongation force decrease. Eventually, more volume of the polymer is drawn which leads to an increase in the fiber diameter. A similar correlation effect between spinning temperature and fiber diameter was also observed by Ko et al. [48]. The contour plot suggests that the optimum range of temperature and speed to draw thin microfiber occur within the spinning temperature region of $160-163^{\circ} \mathrm{C}$ and $285 \mathrm{rpm}-340 \mathrm{rpm}$ respectively.

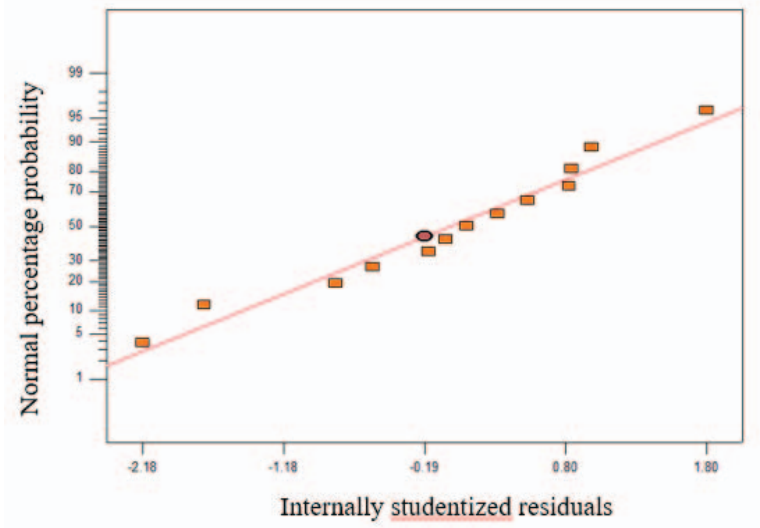

Fig. 6: Studentized residuals and normal percentage probability plot for the melt spinning of PLA_Cur_PPC 30 fibers.

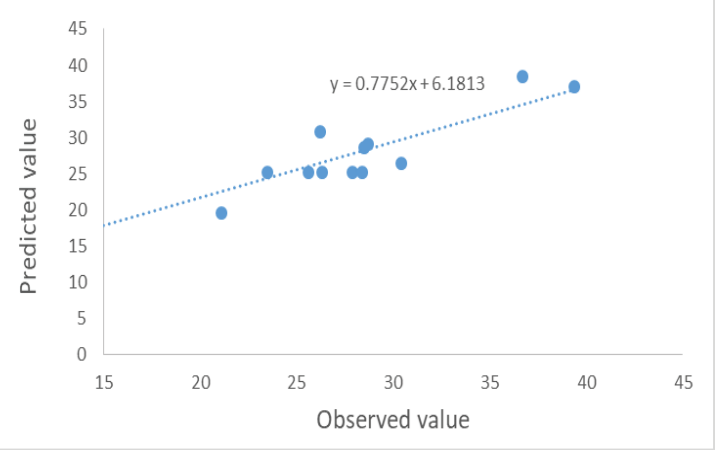

Fig. 7: Plot of observed values versus the predicted values obtained from the reduced fitted regression line obtained for 
the melt spinning of PLA_Cur_PPC 30

fibers.

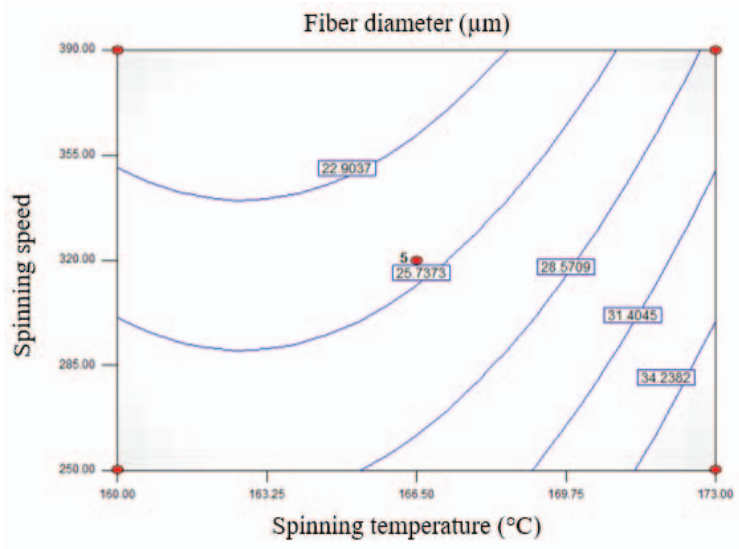

Fig. 8: Contour plot in the design space for $\mathrm{Y}^{\prime}$ (fiber diameter) with respect to $\mathrm{X}_{1}$ (spinning temperature) and $\mathrm{X}_{2}$ (spinning speed) for PLA_Cur_PPC 30 fiber.

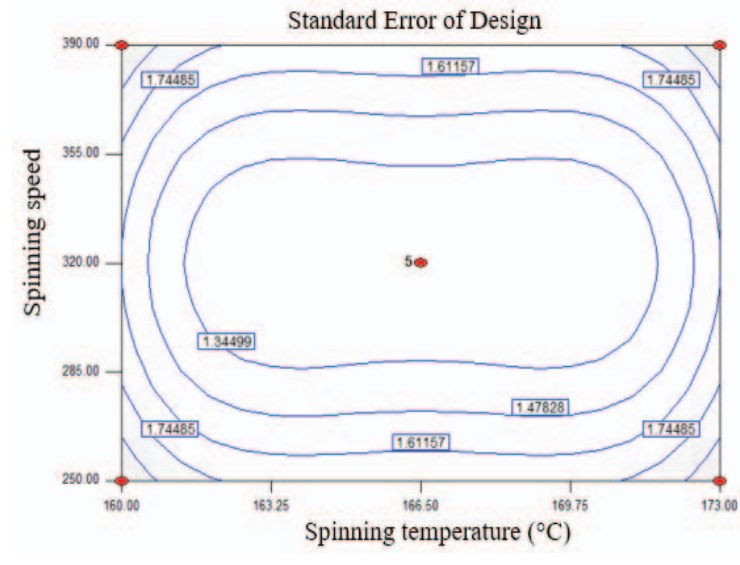

Fig. 9. Plot of standard error of design in the design space for $\mathrm{Y}^{\prime}$ (fiber diameter) with respect to $X_{1}$ (spinning temperature) and $X_{2}$ (spinning speed) for PLA_Cur_PPC 30 fiber.

Fig. 9 represents the standard error estimation based on several numbers of observations made at the centre point $(0,0)$ (Aslan, 2007) of the two-factor CCD approach. If the number of observations/replicates at the centre point is too high, then the farther points from the centre will yield a rapid increase in standard error estimations (Clark \& Williges, 1973). On the contrary, if the number of replicates is too low at the centre point, this would yield a reversing effect in which the error estimation would be greater at the centre compared to other data points. Having a constant error contour throughout the design space is highly desirable as this would justify that the error estimate calculated at the centre point is a good representative of the error estimate throughout the design space. It can be observed from Fig. 9 that the error estimation is not the same throughout the experimental domain. The standard error is reasonably uniform over a large design space near the centre and the error contours slowly increase as the data points reach the design space boundaries which suggest that the response model may not deliver accurate predictions for diameter governed by extreme values of the design space.

\subsection{Fiber Morphology}

The fiber diameter measured using optical microscope revealed that they averaged between 15 to 40 microns (see Fig. 10). Fig. 11 shows the fiber bundle from each test run observed via SEM. It was also noted that there was irregular formation of bead-like structure on the lateral surface of the fiber as shown in Fig. 12. It is postulated that such surface condition occurred due to the partial dispersion of curcumin particles in the PLA/PPC blend. A similar textured or bead-like surface effect was also obtained for melt-spun fibers from the polypropylene/soy particle blend [51] and the polypropylene/talc blend [52]. Contrary to the perception that such textured surface is undesirable, this bead-like surface is actually a unique feature because it imitates the tactile feel of the irregular cross-section and highly crenulated structure of natural fibers such as those found in cotton [51]. 


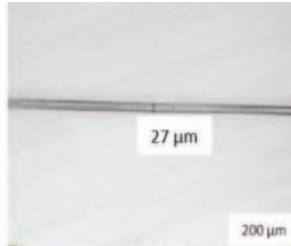

Run $1: 169^{\circ} \mathrm{C}, 221 \mathrm{rpm}$

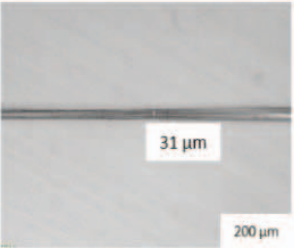

Run 6: $157^{\circ} \mathrm{C}, 320 \mathrm{rpm}$

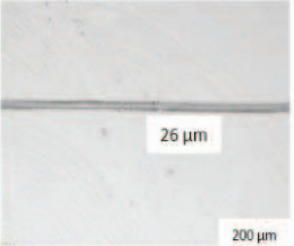

Run $11: 167^{\circ} \mathrm{C}, 320 \mathrm{rpm}$

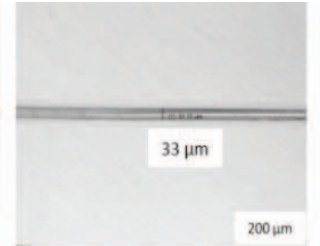

Run 2: $173^{\circ} \mathrm{C}, 390 \mathrm{rpm}$

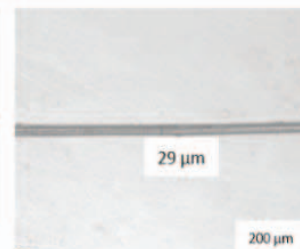

Run $7: 167^{\circ} \mathrm{C}, 320 \mathrm{rpm}$

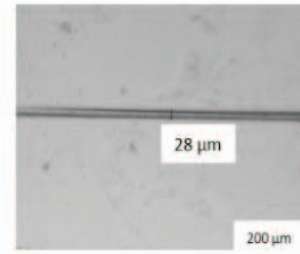

Run $12: 167^{\circ} \mathrm{C}, 320 \mathrm{rpm}$

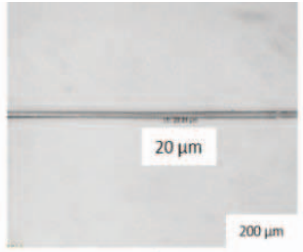

Run 3: $160^{\circ} \mathrm{C}, 390 \mathrm{rpm}$

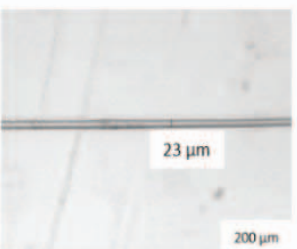

Run $8: 167^{\circ} \mathrm{C}, 419 \mathrm{rpm}$

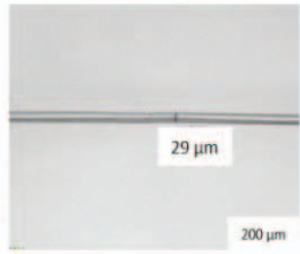

Run $13: 173^{\circ} \mathrm{C}, 250 \mathrm{rpm}$
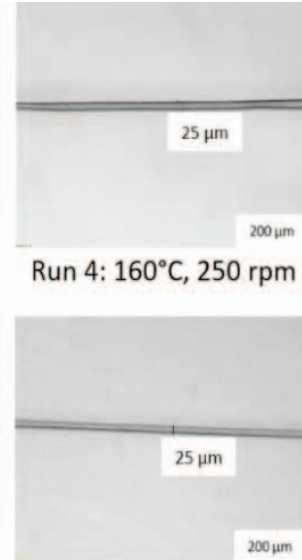

Run 9: $167^{\circ} \mathrm{C}, 320 \mathrm{rpm}$
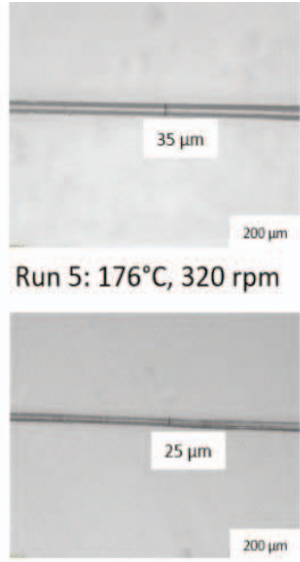

Run $10: 167^{\circ} \mathrm{C}, 320 \mathrm{rpm}$

Fig. 10: SEM images (200x) of PLA_Cur_PPC 30 fiber spun at each CCD design matrice.

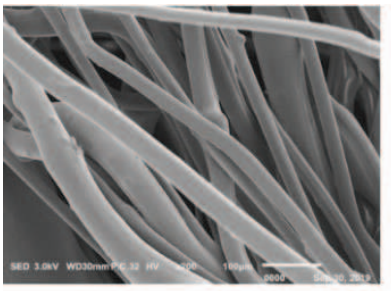

Run 1: $169^{\circ} \mathrm{C}, 221 \mathrm{rpm}$

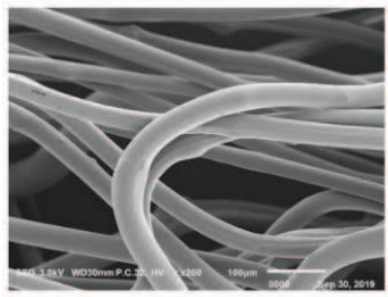

Run 5: $176^{\circ} \mathrm{C}, 320 \mathrm{rpm}$

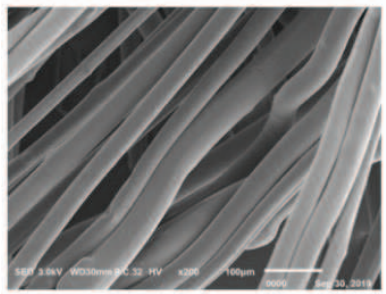

Run $13: 173^{\circ} \mathrm{C}, 250 \mathrm{rpm}$

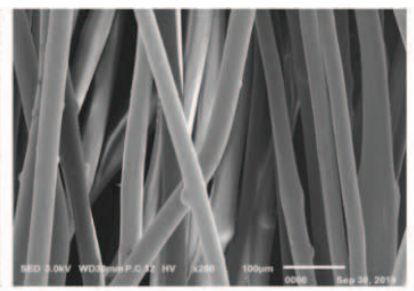

Run 2: $173^{\circ} \mathrm{C}, 390 \mathrm{rpm}$

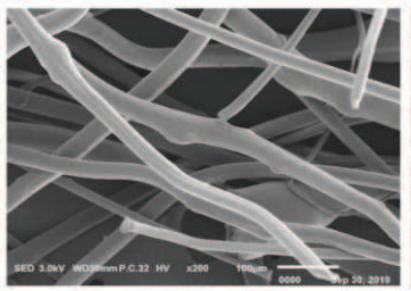

Run 6: $157^{\circ} \mathrm{C}, 320 \mathrm{rpm}$

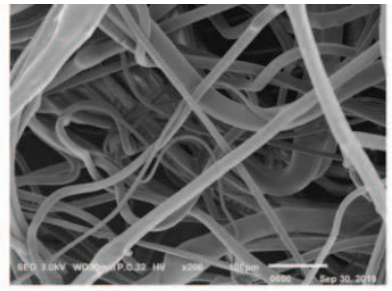

Run 3: $160^{\circ} \mathrm{C}, 390 \mathrm{rpm}$

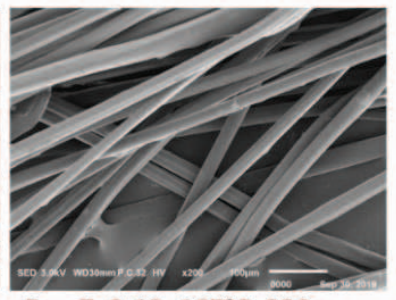

Run 7, 9-12: $167^{\circ} \mathrm{C}, 320 \mathrm{rpm}$

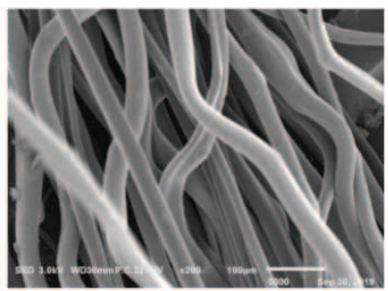

Run $4: 160^{\circ} \mathrm{C}, 250 \mathrm{rpm}$

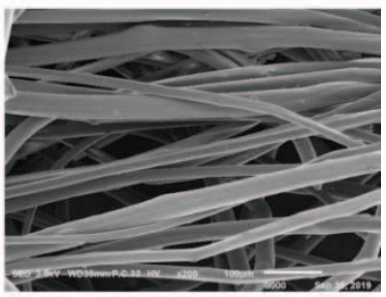

Run 8: $167^{\circ} \mathrm{C}, 419 \mathrm{rpm}$

Fig. 11: Images of randomly taken fiber diameter measured via optical microscope for PLA_Cur_PPC 30 fiber. 


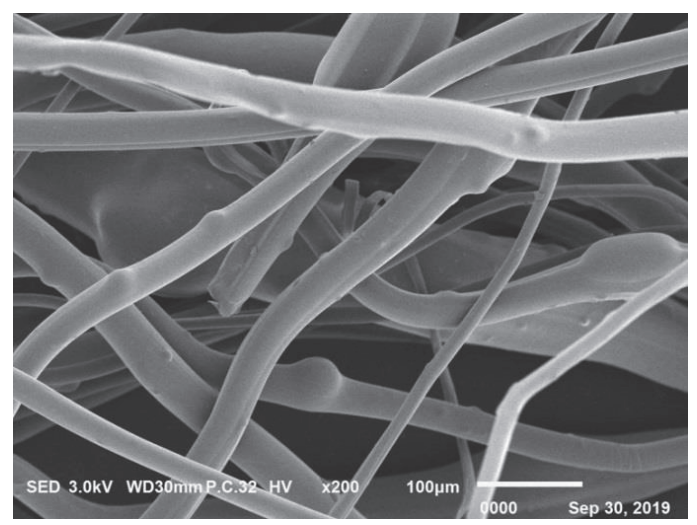

Fig. 12: SEM image showing the irregular formation of bead-like structure on the lateral surface of the fiber.

\section{CONCLUSION}

This study revealed that the substantial inclusion of PPC up to $30 \mathrm{wt} \%$ into PLA/curcumin blends did not result in appreciable change in strength due to the reinforcement effect of curcumin. The modulus values increased due to favourable dispersion of curcumin in the less viscous PPC, which aids in constraining the polymer chain movement. However, further additions of the more flexible PPC at $40 \mathrm{wt} \%$ were accompanied by an increasing toughness and vice versa effect in strength and modulus. PLA_Cur_PPC 30 was then identified for further study via RSM. It was concluded from the response model that spinning temperature had a more dominant effect on the fiber diameter in comparison to spinning speed due to its direct influence on the surface tension and melt viscosity. The response model also indicated a good correlation between experimental and predicted values based on all the criteria defined in this study.

\section{ACKNOWLEDGEMENTS}

This work was fully supported by International Islamic University Malaysia, IIUM (RIGS17-052-0627). The authors would like to express their deepest gratitude to facilities and technical assistance provided by International Institute for Halal Research and Training (INHART), IIUM.

\section{REFERENCES}

[1] Lyu S, Untereker D. (2009) Degradability of polymers for implantable biomedical devices. Int. J. Mol. Sci., 9:4033-4065.

[2] Xiaon L, Wang B, Yang G, Gauthier M. (2011) Poly(lactic acid)-based biomaterials: Synthesis, modification and applications. Biomedical Science, Engineering and Technology, Intech, Croatia.

[3] Casalini T, Rossi F, Castrovinci A, Perale G.(2019) A perspective on polylactic acid-based polymers use for nanoparticles synthesis and application. Front. Bioeng. Biotechnol., 7:1-16.

[4] Liu L, Wei H, Wang Z, Li Q, Tian N. (2018) Simultaneous enhancement of strength and toughness of PLA induced by miscibility variation with PVA. Polymers, 10(10):1178.

[5] Saini P, Arora M, Kumar MR. (2016) Poly(lactic acid) blends in biomedical applications. Adv. Drug Deliv., 107: 47-59. 
[6] Qin SX, Yua CX, Chen XY, Zhoua HP, Zhao LF (2018) Fully biodegradable poly(lactic acid)/poly(propylene carbonate) shape memory materials with low recovery temperature based on in situ compatibilization by dicumyl peroxide. Chinese J Ploym Sci., 36:783-790.

[7] Gao L, Huang M, Wu Q, Wan X, Chen X, Wei X, Yang W, Deng R, Wang L, Feng J. (2019) Enhanced poly(propylene carbonate) with thermoplastic networks: A cross-linking role of maleic anhydride oligomer in CO2/PO copolymerization. Polymers., 11:1467-1479.

[8] Wang S, Huang Y, Liao B, Lin G, Cong G, Chen L. (1997) Structure and properties of poly(propylene carbonate). Int J Polym Ch. 3(2):131-143.

[9] Yao M, Deng H, Ma F, Wang K, Zhang Q, Chen F, Fu Q. (2011) Modification of poly(lactic acid)/poly(propylene carbonate) blends through melt compounding with maleic anhydride. Polym Lett, 5(11):937-949.

[10] Ning W, Xingxiang Z, Jiugao Y, Jianming F. (2008) Partially miscible poly(lactic acid)blend-poly(propylene carbonate) flled with carbon black as conductive polymer composite. Polym Int., 57:1027-1035.

[11] Ma X, Yu J, Wang N. (2006) Compatibility characterization of poly(lactic acid)/poly(propylene carbonate) blends. J Polym Sci Phys., 44(1):94-101.

[12] Aggarwal B, Sung B. (2009) Pharmacological basis for the role of curcumin in chronic diseases: An age-old spice with modern targets. Trends Pharmacol Sci., 30(2):85-94

[13] Prasad S, Tyagi AK, Aggarwal BB. (2014) Recent developments in delivery, bioavailability, absorption and metabolism of curcumin: the golden pigment from golden spice. Cancer Res Treat., 46(1):2-18.

[14] Ramalingam N, Natarajan TS, Rajiv S. (2015) Preparation and characterization of electrospun curcumin loaded poly(2-hydroxyethyl methacrylate) nanofiber--a biomaterial for multidrug resistant organisms. J. Biomed. Mater. Res. Part A, 103(1):16-24.

[15] Morais DS, Guedes RM and Lopes MA. (2016) Antimicrobial approaches for textiles: From research to market. Materials, 9(6):498.

[16] Xia F, Chun Z, Dong-bo L, Jun Y, Hua-ping L. (2013) The clinical applications of curcumin: Current state and the future. Curr. Pharm. Des., 19(11):2011-2031.

[17] Yan C, Jie L, Yuqin W, Yanna F, Hongbo W, Weidong G. (2012) Preparation and blood compatibility of electrospun PLA/Curcumin composite membranes. Fiber Polym., 13(10):1254-1258.

[18] Chen Y, Lin J, Fei Y, Wang H, Gao W (2010) Preparation and characterization of electrospinning PLA/Curcumin composite membranes. Fiber Polym., 11(8):1128-1131.

[19] Weldon CB, Tsui JH, Shankarappa SA, Nguyen VT, Ma M, Anderson DG, Kohane DS. (2012) Electrospun drug-eluting sutures for local anesthesia. J Control Release, 161:903-909.

[20] Yördem OS, Papila M, Mencelog lu Y. (2008) Effects of electrospinning parameters on polyacrylonitrile nanofiber diameter: An investigation by response surface methodology. Mater Design, 29:34-44.

[21] Mohamed OA, Masood SH, Bhowmik JL. (2015) Optimization of fused deposition modeling process parameters: a review of current research and future prospects. Adv Manuf., 3(1):4253.

[22] Ghoreishian SM, Fereydooni A, Nasser S, Asadolahi T, Beigpour N, Ghoreishian M. (2017) Optimization of melt-spinning parameters of poly(ethylene terephthalate) partially oriented multi-filament yarn in an industrial scale: Central composite design approach. Fiber Polym., 18:1280-1287.

[23] Garnier L, Duquesne S, Casetta M, Lewandowski M, Bourbigot S (2010) Melt spinning of silane-water cross-linked polyethylene-octene through a reactive extrusion process. React Funct Polym., 70(10):775-783. 
[24] Shu-Ying G, Jie R. (2005) Process optimization and empirical modeling for electrospun poly(D,L-lactide) fibers using response surface methodology. Macromol Mater Eng., 290 (11):1097-1105.

[25] Dhura B, Saraswathy N, Maheswaran R, Sethupathi P, Vanitha P, Vigneshwaran S, Rameshbabu V. (2013) Electrospinning of curcumin loaded chitosan/poly (lactic acid) nanofilm and evaluation of its medicinal characteristics. Front Mater Sci., 7(4):350-361.

[26] Sharifah ISS, Qairol AAB, Noor Azlina H, Nor Khairusshima MK (2017) Thermal, structural and mechanical properties of melt drawn curloaded poly(lactic acid) fibers. Procedia Eng., 184:544-551.

[27] Yuan X, Mak AF, Kwok KW, Yung BK, Yao K. (2001) Characterization of poly(L-lactic acid) fibers produced by melt spinning. J App Polym Sci., 81:251-260.

[28] Pawar RP, Tekale SU, Shisodia SU, Totre JT, Domb AJ (2014) Biomedical applications of poly(lactic acid). Recent Pat Regen Med., 4:40-51.

[29] Behera SK, Meena H, Chakraborty S, Meikap BC. (2018) Application of response surface methodology (RSM) for optimization of leaching parameters for ash reduction from lowgrade coal. Int. J. Min. Sci. Technol., 28 (4):621-629.

[30] Shah SAA, Imran M, Lian Q, Shehzad FK, Athir N, Zhang J, Cheng J. (2018) Curcumin incorporated polyurethane urea elastomers with tunable thermomechanical properties. React Funct Polym., 128:97-103.

[31] Yu C, Zhao R, Wang H. (2018) Mechanical property of PLA/PPC blends. Int J Trend Res Dev., 5(2):206-208.

[32] Liu H, Zhang J. (2011) Research progress in toughening modification of poly(lactic acid). J Polym Sci Pol Phys., 49:1051-1083.

[33] Liu Y, Cai Y, Jiang X, Wu J, Le X. (2015) Molecular interactions, characterization and antimicrobial activity of curcumin-chitosan. Food Hydrocoll., 52:564-572.

[34] Kim DK, Kim JI, Sim BR, Khang G. (2017) Bioengineered porous composite curcumin/silk scaffolds for cartilage regeneration. Mater Sci Eng C., 78:571-578.

[35] Muthuraj R, Mekonnen T. (2018) Recent progress in carbon dioxide (CO2) as feedstock for sustainable materials development: Co-polymers and polymer blends. Polymer, 145:348-373.

[36] Deng Y, Yu C, Wongwiwattana P, Thomas NL. (2018) Optimising ductility of poly(lactic acid)/poly(butylene adipate-co-terephthalate) blends through co-continuous phase morphology. J Polym Environ., 26:3802-3816.

[37] Gao J, Bai H, Zhang Q, Gao Y, Chen L, Fu Q. (2012) Effect of homopolymer poly(vinyl acetate) on compatibility and mechanical properties of poly(propylene carbonate)/poly(lactic acid) blends. Polym Lett., 11:860-870.

[38] Haneef INHM, Shaffiar NM, Buys YF, Hamid M, Shaharuddin SIS. (2018) Morphologies and mechanical properties of polylactic acid / polypropylene carbonate (PLA/PPC) blends by solvent casting method. In Proceedings of the International Conference Biotechnology Engineering : September 19-20, Kuala Lumpur.

[39] Mofokeng J, Luyt A. (2015) Morphology and thermal degradation studies of melt-mixed poly(lactic acid) (PLA)/poly(E-caprolactone) (PCL) biodegradable polymer blend nanocomposites with $\mathrm{TiO}_{2}$ as filler. Polym Test, 45:93-100.

[40] Nocke A, Wolf M. (2012) Nanoparticle-based Resistors and Conductors in Bio and Nano Packaging Techniques for Electron Devices: Advances in Electronic Device Packaging. Springer-Verlag, Berlin.

[41] Kim SY, Noh YJ, Yu J. (2015) Thermal conductivity of graphene nanoplatelets filled composites fabricated by solvent-free processing for the excellent filler dispersion and a theoretical approach for the composites containing the geometrized fillers. Compos Part A Appl Sci Manuf., 69:219-225. 
[42] Wu D, Zhang Y, Zhang M, Yu W. (2009) Selective localization of multiwalled carbon nanotubes in poly ( $\varepsilon$-caprolactone)/polylactide blend. Biomacromolecules, 10:417-424.

[43] Asmatulu R, Khan WS. (2019) Synthesis and applications of electrospun nanofibers. Elsevier, Amsterdam.

[44] Vlachopoulos J, Strutt D. (2003) The role of rheology in polymer extrusion. In Proceedings of the Extrusion Minitec and Conference: From Basics to Recent Developments: $26^{\text {th }}$ October 2004, Du"sseldorf; pp 107-132.

[45] Kong C, Jo K, Jo HKNK. (2009) Effects of the spin line temperature profile and melt index of poly(propylene) on melt-electrospinning. Polym Eng Sci., 49(2):391-396.

[46] M. Niaounakis (2015) Biopolymers: Applications and Trends, Elsevier, Oxford.

[47] Nayak R, Padhye R, Kyratzis IL, Truong YB, Arnold L. (2013) Effect of viscosity and electrical ccnductivity on the morphology and fiber diameter in melt electrospinning of polypropylene. Text Res., 83(6):606-617.

[48] Ko J, Jun S, Lee JK, Lee PC, Jun MB. (2015) Effects of molecular weight and temperature on fiber diameter of poly ( $\varepsilon$-caprolactone) melt electrospun fiber. J. Korean Soc Manuf Technol Eng., 24(2):160-165.

[49] Aslan N. Application of response surface methodology and central composite rotatable design for modeling the influence of some operating variables of a multi-gravity separator for coal cleaning. Fuel, 86(5-6):769-776.

[50] Clark C, Williges RC. (1973) Response surface methodology central-composite design modifications for human performance research. Human Factor, 15(4):295-310.

[51] Guzdemir O, Ogale AA. (2019) Influence of spinning temperature and filler content on the properties of melt-spun soy flour/polypropylene fibers. Fibers, 7(10):83-101.

[52] Tascan M, Nohut S. (2016) Melt-spun talc-filled polypropylene fibers and yarns with higher thermal shock resistance. Text Res J., 87(1):31-45. 